\title{
Comparing the life cycle costs of using harvest residue as feedstock for small- and large-scale bioenergy systems (part II)
}

\author{
J. Cleary, D. Wolf, J. Caspersen
}

Version Post-print/Accepted Manuscript

Citation Cleary, Julian et al. "Comparing the life cycle costs of using harvest (published version) residue as feedstock for small- and large-scale bioenergy systems (part II).” Energy 86 (2015): 539-547.

DOI: https://doi.org/10.1016/j.energy.2015.04.057

Copyright/License

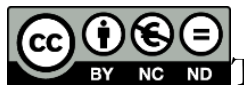

This work is licensed under the Creative Commons Attribution-NonCommercial-NoDerivatives 4.0 International License. To view a copy of this license, visit Creative Commons BY NC ND 4.0 License.

How to cite TSpace items

Always cite the published version, so the author(s) will receive recognition through services that track citation counts, e.g. Scopus. If you need to cite the page number of the author manuscript from TSpace because you cannot access the published version, then cite the TSpace version in addition to the published version using the permanent URI (handle) found on the record page.

This article was made openly accessible by $U$ of $T$ Faculty. Please tell us how this access benefits you. Your story matters. 
1 Comparing the life cycle costs of using harvest residue as feedstock for small- and

2 large-scale bioenergy systems (Part II)

3

4 Julian Cleary ${ }^{\dagger}$, Derek P. Wolf ${ }^{\dagger}$, John P. Caspersen * ${ }^{\dagger}$

5

$6{ }^{*}$ Corresponding author phone: (416) 946-8506, fax: (416) 978-3834, e-mail:

7 john.caspersen@utoronto.ca

$8+$ Faculty of Forestry, University of Toronto, 33 Willcocks St., Toronto, Ontario,

9 Canada

$10 \quad$ M5S 3B3

11

12 Abstract

13

14 In part II of our two-part study, we estimate the nominal electricity generation and

15 greenhouse gas (GHG) mitigation costs of using harvest residue from a hardwood forest

16 in Ontario, Canada to fuel (1) a small-scale $\left(250 \mathrm{~kW}_{\mathrm{e}}\right)$ combined heat and power wood

17 chip gasification unit and (2) a large-scale $\left(211 \mathrm{MW}_{\mathrm{e}}\right)$ coal-fired generating station

18 retrofitted to combust wood pellets. Under favorable operational and regulatory

19 conditions, generation costs are similar: 14.1 and 14.9 cents per $\mathrm{kWh}(\mathrm{c} / \mathrm{kWh})$ for the

20 small- and large-scale facilities, respectively. However, GHG mitigation costs are

21 considerably higher for the large-scale system: $\$ 159 /$ tonne of $\mathrm{CO}_{2}$ eq., compared to $\$ 111$

22 for the small-scale counterpart. Generation costs increase substantially under existing

23 conditions, reaching: (1) $25.5 \mathrm{c} / \mathrm{kWh}$ for the small-scale system, due to a regulation 
1 mandating the continual presence of an operating engineer; and (2) $22.5 \mathrm{c} / \mathrm{kWh}$ for the

2 large-scale system due to insufficient biomass supply, which reduces plant capacity factor

3 from $34 \%$ to $8 \%$. Limited inflation adjustment (50\%) of feed-in tariff rates boosts these

4 costs by $7 \%-11 \%$. Results indicate that policy generalizations based on scale require

5 careful consideration of the range of operational/regulatory conditions in the jurisdiction

6 of interest. Further, if GHG mitigation is prioritized, small-scale systems may be more

7 cost-effective.

\section{$9 \quad$ Highlights}

10 - Generation costs for two forest bioenergy systems of different scales are

$11 \quad$ estimated

12 - Nominal electricity costs are 14.1 to 28.3 cents/kWh for the small-scale plant

13 - Nominal electricity costs are 14.9 to 24.2 cents/kWh for the large-scale plant

14 - GHG mitigation costs from displacing coal and LPG are \$111-\$281/tonne of $\mathrm{CO}_{2}$

15 eq.

16 - High sensitivity to cap. factor (large-scale) and labour requirements (small-scale)

\section{Keywords}

19 bioenergy; biomass; GHG mitigation; harvest residue; life cycle costing; scale 


\section{Introduction}

4 The high cost of producing electricity from biomass is widely considered to be a

5 primary impediment to increasing bioenergy supply and realizing associated economic

6 and environmental benefits $[1,2,3]$. To overcome this economic barrier, many

7 governments offer subsidies to encourage investment in bioenergy technologies.

8 However, effective policy design is challenged by the considerable variation in bioenergy

9 generation costs resulting from numerous operational and regulatory conditions that are

10 specific to individual projects and jurisdictions, including conversion efficiency, fuel

11 supply and subsequent capacity factor, financing costs, expected returns, and differing

12 regulatory requirements [4]. Yet, there is one cost consideration that consistently

13 determines the level of subsidization: bioenergy production costs, outside of the cost of

14 feedstock, tend to decrease with scale, or the rated capacity of the system (e.g., [5, 6, 7]).

15 Thus, supply-side subsidy programs often provide greater financial support for smaller-

16 scale projects within a given technology class.

17 Feed-in tariff (FIT) programs, which offer fixed payment rates for the production

18 of renewable electricity, demonstrate considerable inter-jurisdictional variability in the

19 number of technology classes, scales, and related provisions that are taken into account.

20 In a comparison of the FIT programs of Ontario (Canada) and Germany, Mabee et al. [8]

21 noted that the Ontario program differentiates between two bioenergy scales, whereas the

22 German program differentiates between four scales. A number of provisions ("adders")

23 are available through the German program for specific aspects of bioenergy projects that 
1 result in desirable auxiliary benefits (e.g., waste heat utilization) [8]. There are also

2 differences in the treatment of the contract over time: in Ontario, an annual FIT rate

3 escalation is present, but not fully indexed to inflation [8], whereas the FIT rate for

4 bioenergy facilities under the German program does not change throughout the lifetime

5 of the contract [9]. These program details can have important consequences for attracting

6 investment in bioenergy capacity. Studies have shown that the rates offered for bioenergy

7 are often misaligned with actual generation costs, including those of Ontario's FIT

8 program [4]. The Ontario FIT rate for bioenergy projects smaller than $500 \mathrm{~kW}_{\mathrm{e}}$ has

9 recently been increased from 13.8 to 15.6 cents $/ \mathrm{kWh}(\mathrm{c} / \mathrm{kWh})$, whereas projects larger

10 than $500 \mathrm{~kW}_{\mathrm{e}}$ are now ineligible for FIT subsides, which have been replaced with a

11 bidding/auction mechanism for large projects $[10,11]$. Previously, bioenergy projects

12 larger than $10 \mathrm{MW}_{\mathrm{e}}$ commanded a FIT of $13.0 \mathrm{c} / \mathrm{kWh}$ [11]. Relative to scale, German

13 FITs for biomass technologies have differed to a much greater extent, starting at 0.08

$14 € / \mathrm{kWh}$ for a plant $\leq 20 \mathrm{MW}_{\mathrm{e}}$, and reaching 0.12 to $0.22 € / \mathrm{kWh}$ for small-scale plants 150

$15 \quad \mathrm{~kW}_{\mathrm{e}}$ and under [8].

16 Most bioenergy subsidization initiatives acknowledge that generation costs, and

17 subsidy requirements per unit of electricity generated, decrease as the rated electrical

18 capacity of bioenergy facilities increases. However, unlike fossil fuel-based electricity

19 generation projects, fuel procurement costs for bioenergy systems rise rapidly with scale,

20 a function of the relatively low spatial distribution density, energy density, and bulk

21 density of biomass [7, 12, 13]. These unfavorable properties of biomass have constrained

22 the scales of bioenergy facilities in North America since the 1980s to an average of

23 approximately $20 \mathrm{MW}_{\mathrm{e}}$ [14]. With the exception of a few recent co-firing projects in 
1 northwestern Europe, supply constraints have reduced co-firing rates to an average of

$22.8 \%$ [15]. In Ontario, initial plans to retrofit coal-fired generating stations to combust

3 wood pellets included a provision that all wood pellet inputs must be derived from in-

4 province biomass supplies. This further constrains biomass supply opportunities and has

5 limited the capacity factor (the ratio of actual output to potential output, based on the

6 nameplate capacity of the facility) of a retrofitted coal-fired generating station in the

7 province to $8 \%[16]$.

8 As bioenergy sectors grow, low cost biomass supplies such as sawmill residue

9 will become fully utilized, requiring procurement of higher cost biomass sources [17, 18].

10 The contribution of forest-origin biomass (including roundwood and harvest residue), to

11 total biomass supply is expected to increase in jurisdictions with active forest sectors, as

12 has been observed in Finland and Sweden [19]. Harvest residue (stem tops, branches, and

13 small-diameter unmerchantable trees) is the lowest cost source of biomass that can be

14 procured from forest operations because the fixed costs of the machinery used in these

15 operations are already borne by the recovered merchantable roundwood, and there are

16 usually no alternative economic uses for the residue. However, the amount of residue

17 generated per hectare is equivalent to only a small portion of roundwood production,

18 requiring a larger theoretical procurement radius relative to roundwood, for a given

19 facility scale. Hence, with harvest residue as the main supply source, small-scale systems

20 (e.g., $<500 \mathrm{~kW}_{\mathrm{e}}$ ), when appropriately sited, could have lower generation costs than large-

21 scale systems because the lower annual biomass demand can maintain procurement costs

22 within acceptable limits. Given the additional GHG benefits of utilizing harvest residue

23 for energy [20, 21], future iterations of bioenergy subsidy programs would benefit from a 
1 better understanding of the relative costs of small- and large-scale bioenergy facilities

2 utilizing harvest residue as the main fuel source.

3 In addition to biomass supply constraints, there are additional context-sensitive

4 factors that can also serve to reduce the subsidy requirements of small-scale systems

5 relative to large-scale systems. Small-scale combined heat and power (CHP) facilities

6 that are co-located with industrial facilities or district heating networks can have potential

7 revenue advantages relative to large-scale facilities, which tend to lack proximal heat

8 demand [22]. For example, costs of electricity generation fall from 18 to $11 \mathrm{c} / \mathrm{kWh}$ when

9 taking into account the economic value of heat recovered in small-scale biomass

10 gasification CHP systems [23]. With regard to GHG mitigation costs, large-scale systems

11 tend to have higher supply chain emissions, such as those from additional feedstock

12 transportation and processing [24, 25, 26]. While electricity generation costs may still be

13 larger for small-scale systems, GHG mitigation costs can drop below those of larger-scale

14 systems due to the improved GHG savings. When considering the potential revenues on

15 carbon markets, the relative subsidy amount required for small-scale systems may further

16 decrease. Conversely, small-scale systems may have larger subsidy requirements in

17 jurisdictions like Ontario, which has a regulation mandating the continual presence of an

18 operating engineer [27], even though unnecessary for certain system designs [4, 28].

19 In this paper, part II of a two-part study (Part I: [29]), we compare the life cycle

20 costs of using harvest residue procured from a hardwood forest in Ontario in a small- and

21 a large-scale bioenergy facility. The small-scale bioenergy facility is a hypothetical wood

22 chip-fuelled combined heat and power (CHP) gasification system (250 kW $\mathrm{k}$ unit) (System

23 1), whereas the large-scale bioenergy facility is a coal-fired generating station retrofitted 
1 to combust wood pellets that is currently operational in Ontario (211 $\mathrm{MW}_{\mathrm{e}}$ unit) (System

2 2). Our analysis estimates the cost of electricity production, and hence the FIT rates that

3 would be necessary to allow bioenergy to compete with lower cost electricity from coal

4 and other fossil fuels. GHG mitigation costs are also estimated in order to assess which

5 system meets this policy objective at lower cost. The sensitivity of the results to capacity

6 factor, operating expenses, and FIT escalation rates is explored for each system through

7 the use of two scenarios representative of different operational and regulatory conditions

8 in the province. Results are further qualified using sensitivity analysis, and discussed in

9 relation to Ontario's FIT policy.

\section{$11 \quad 2$ Methods}

\section{$13 \quad 2.1$ Study area, scenarios, and system boundary}

As in Part I of our study which pertains only to life cycle GHG emissions and

16 impacts, the life cycle costing (LCC) is based on the use of harvest residue collected from

17 the Haliburton Forest and Wildlife Reserve (HFWR), a privately-owned forest located in

18 the Great Lakes-Saint Lawrence forest region of southern Ontario. The residue would be

19 collected via the modification of a conventional single-tree selection operation, producing

20 an average of 1.9 dry tonnes of biomass per hectare (dt/ha) in the form of small-diameter

21 roundwood [30]. The collected residue would be processed and supplied to either (1) a

22 hypothetical $250 \mathrm{~kW}_{\mathrm{e}} \mathrm{CHP}$ gasification facility installed at the HFWR sawmill using

23 wood chips as fuel (System 1); or (2) an existing $211 \mathrm{MW}_{\mathrm{e}}$ coal-fired generating station 
1 in Atikokan, Ontario retrofitted to combust wood pellets, generating electricity only

2 (System 2).

3 Each system is evaluated under two scenarios that are differentiated on the basis

4 of key parameters related to operational and regulatory conditions. One scenario

5 represents favourable conditions (S1a and S2a) from a bioenergy project cost perspective,

6 and the other represents current conditions in Ontario (S1b and S2b). Differences

7 between S1a and S1b relate to operation and maintenance (O\&M) costs, whereas

8 capacity factor, which is itself a function of the total annual biomass supply (further

9 described in Section 3), differs between S2a and S2b. To account for the possibility that

10 FIT escalation rates are adjusted, the scenarios modelled under favourable conditions

11 (S1a and S2a) include an escalation rate that is equivalent to the Consumer Price Index

12 (CPI) inflation rate (3\%/year as in Moore et al., [4]), whereas the scenarios modelled

13 under current conditions ( $\mathrm{S} 1 \mathrm{~b}$ and $\mathrm{S} 2 \mathrm{~b}$ ) include an escalation rate that is equivalent to

14 half of the CPI inflation rate (1.5\%/year). Thus, the favourable operational and regulatory

15 conditions, relative to existing conditions, incorporate the following assumptions: (1) the

16 removal of the requirement that an operating engineer must be present at all times while

17 the bioenergy facility is in operation (see Section 2.3.5); (2) an increase in the capacity

18 factor of the large-scale system from $8 \%$ to $34 \%[16,26]$; and (3) an increase in the feed-

19 in tariff (FIT) escalation rate to fully compensate for cost inflation.

20 The system boundary of the LCC includes the following life cycle stages: harvest

21 residue collection, transportation, processing into wood chips or pellets, gasification /

22 combustion, and ash waste management. Whereas capital costs are included in the LCC

23 inventory for the $250 \mathrm{~kW}_{\mathrm{e}}$ CHP facility (System 1), the design and installation expenses 
1 associated with the Atikokan coal-fired generating station (System 2), built in the 1980s,

2 are considered sunk costs [26], and are therefore outside of the system boundary.

3 However, those associated with modifying the facility to use wood pellets are included.

4 The savings from the displacement of electricity and/or heat from conventional sources

5 are taken into account when estimating GHG mitigation costs. The electricity displaced

6 by both systems is assumed to be derived from the combustion of coal, as in Zhang et al.

7 [26]. Similar to Danon et al. [31], we assume that heat recovered from the CHP facility is

8 allocated to a wood kiln. The savings from displaced liquefied petroleum gas (LPG) for

9 heat production in System 1 are based upon the amount currently used for the drying of

10 lumber at HFWR.

\section{$12 \quad 2.2$ Life cycle costing and net present value models}

Our LCC model evaluates the financial expenses within the system boundary,

15 including capital and equipment procurement, labour, equipment operation and

16 maintenance $(\mathrm{O} \& \mathrm{M})$, financing, taxes, and returns to capital investment. A 20 year

17 project life is assumed for both bioenergy systems. For the small-scale CHP facility, this

18 estimate is the midpoint of the 25 year assumption of Dornburg and Faaij [6], and the 15

19 year assumption of Wood and Rowley [32]. The 20 year estimate for the Atikokan

20 facility using $100 \%$ wood pellets is from Zhang et al. [26]. An $8 \%$ nominal interest rate

21 for project financing is selected due to its widespread adoption for forest bioenergy

22 projects (e.g., [33]). As in Moore et al. [4], it is assumed that $60 \%$ of the capital costs of

23 the gasification/combustion equipment and infrastructure are debt financed (we assume a 
120 year loan with monthly payments, and an $8 \%$ interest rate), with the remaining $40 \%$

2 equity financed. The internal rate of return (IRR) is assumed to be $9 \%$ (annual return)

3 over the 20 year project life, equal to the weighted average cost of capital, which takes

4 into account the $10.5 \%$ expected return on equity of Ontario Power Generation [34]. The

5 annual depreciation rate is set at 5\% (straight line method), based on the 20 year

6 projected lives of the projects. A 32\% corporate tax rate for Ontario, Canada is used,

7 based on 2010 figures [35, 36]. Nominal life cycle costs are expressed per one kWh of

8 electricity generated, with year one costs in 2010 Canadian dollars.

9 Gross after-tax costs in project year $t\left(C_{t}\right)$ encompass the costs of residue

10 collection $\left(N_{t}\right)$, residue and/or wood pellet transportation $\left(T_{t}\right)$, processing $\left(P_{t}\right)$, energy

11 conversion via gasification/producer gas combustion or wood pellet combustion $\left(E_{t}\right)$, and $12 \operatorname{taxes}\left(X_{t}\right)$ :

$14 C_{t} \quad=N_{t}+T_{t}+P_{t}+E_{t}+X_{t}$

16 The net present value (NPV) of the two bioenergy facilities is calculated using a

17 standard NPV equation, as depicted in Equation 2. In order for the project to break even

18 over the project life span (y), the NPV of the profit is generally equal to zero. In this case,

19 an NPV of zero would result in a 9\% IRR.

$N P V_{y}=\sum_{t=1}^{y}\left(R_{t}-C_{t}\right) /(1+d)^{t}$

25 In Equation 2, $R_{t}$ represents the revenue in project year $t$, and $d$ is the discount rate, which 26 is equal to the $9 \%$ IRR. The project revenue is equal to the quantity of electricity 
1 generated, multiplied by the contract price per kWh of electricity supplied to the grid.

2 For S1a and S2a, the contract price is escalated by the projected 3\% annual CPI growth.

3 For S1b and S2b, this contract price is escalated by $50 \%$ of the annual CPI growth, in

4 keeping with FIT policy [10].

5 Annual taxes are equal to the tax rate $(Z)$ multiplied by the net annual before-tax

6 revenues, minus depreciation $\left(D_{t}\right)$ of the processing and energy conversion capital:

$8 X_{t}=Z \cdot\left(R_{t}-N t-T t-P t-E t-D_{t}\right)$

\section{$11 \quad 2.3$ Life cycle stages}

\section{$13 \quad$ 2.3.1 Collection of harvest residue during forest operations}

Forest operations at HFWR consist of the following sequential activities: felling

16 and delimbing of trees in the forest stand, extraction of the felled and delimbed trees to

17 landing ("skidding"), and separation of extracted trees into products ("slashing").

18 Products - which include sawlogs, firewood, and small-diameter roundwood (harvest

19 residue) - are subsequently transported to their destination for processing. Since the tree

20 felling and skidding processes would be unaffected by the additional collection of

21 residue, they are excluded from the LCC system boundary. The following equation is

22 employed to isolate the costs of residue collection from those of harvesting conventional

23 roundwood: 
$2 \quad N_{t} \quad=\frac{U \cdot I \cdot H \cdot A}{M}+S \cdot W$

4

5 where $N_{t}$ represents the total cost of collecting the residue over one operating year; $U$ is

6 the expense per productive machine hour of chainsaw use $(\$ 42.60 / \mathrm{PMH}) ; I$ is the

7 percentage increase in time (10.8\%) required for delimbing and topping, based on

8 observations at HFWR from Wolf [30]; $H$ is the conventional annual harvest of wood at

9 HFWR, measured in dry tonnes $(19,468 \mathrm{dt})$, based on the tonnage collected during the

10 2010-2011 harvest year; $A$ is the percentage of the harvest area from which residue is

11 collected, assumed to be $2 / 3(66.7 \%)$ of annual operating area based on consultation with

12 a forest engineer [37]; $M$ is the dry mass of wood cut by chainsaw per PMH (4.8

$13 \mathrm{dt} / \mathrm{PMH}) ; S$ is the expense of processing the wood by the slasher, per dry tonne of

14 biomass $(\$ 5.74 / \mathrm{dt})$; and $W$ is the dry mass of wood residue collected $(1,183 \mathrm{dt})$.

15 The additional cost of collecting the residue is calculated to be $\$ 16.21 / \mathrm{dt}$, or

$16 \$ 19,172 / y r$, excluding cost inflation (Table 1). In order to convert between cubic meters

17 of wood and dry tonnes of wood, density measurements for sugar maple (Acer saccharum

18 - the most commonly harvested tree species at HFWR) from Alemdag [38] are used (616

$19 \mathrm{~kg} / \mathrm{m}^{3}$ dry, $875 \mathrm{~kg} / \mathrm{m}^{3}$ dry and stacked).

\section{$21 \quad$ 2.3.2 Transportation of harvest residue to wood processing site}

23 Shipping the residue to the gasification/wood processing site is estimated to cost

$24 \$ 18.84 / \mathrm{dt}$. This cost is based on the difference between the cost of shipping (1) all of the 
1 merchantable wood harvested in the 2010-2011 harvest season, and (2) the merchantable

2 wood combined with the wood residue. It is assumed that the average capacity of a

3 logging truck is reduced by $40 \%$ when shipping only wood residue instead of

4 conventional roundwood, as in Wolf [30].

5 The cost of transporting the wood residue from the harvest sites to the

6 gasification/wood processing site assumes the use of three self-loading logging trucks at

7 HFWR, which take two trips per day [39], and travel an average one-way distance of 27.3

$8 \mathrm{~km}$ [40]. Each haul includes roundwood destined for the HFWR sawmill, firewood, as

9 well as harvest residue. The portions of the trip distance that are travelled on paved and

10 gravel roads of different grades, each of which is associated with a different truck fuel

11 consumption rate, are based on [41].

12 Costing parameters, including insurance, maintenance and fuel cost, as well as

13 wage per scheduled machine hour (SMH), were supplied by P. Schleifenbaum [42].

14 Generic assumptions pertaining to the purchase price, lifespan, utilization rate, average

15 fuel consumption (varying with road type and truck load), and salvage value of the truck,

16 as well as operating hours per year, are based on estimates from FPInnovations [43],

17 intended to depict harvesting operations in mixed forests in Ontario (Table 2).

\section{$19 \quad$ 2.3.3 Wood biomass processing at gasification and pelletization sites}

The residue chipping costs for the small-scale gasification scenario total $\$ 6.08 / \mathrm{dt}$.

22 The capital cost of the chipping equipment is excluded from this estimate because the

23 wood chipper was already present and used in the HFWR sawmill. Thus, the chipping 
1 cost addresses only electricity use (\$1.02/dt) and maintenance (\$5.06/dt), and is based on

2 the actual costs at HFWR [44] (Table 3).

3 The wood drying cost for Scenario $1(\$ 2.36 / \mathrm{dt})$ is based on (1) the estimated

4 electricity used to dry the chips $(0.025 \mathrm{kWh} / \mathrm{kg}$ water evaporated) [45], (2) the price of

5 electricity used at HFWR (9 c/kWh), and (3) the capital, operating and maintenance costs

6 of a rotating drum kiln with a 15 year lifespan, using the same $60 / 40$ debt/equity ratio

7 assumed for the gasification and combustion infrastructure [46] (Table 3). It is assumed

8 that the heat used for drying the wood to a $15 \%$ moisture content (from $45 \%$, based on

9 [39]) is derived from the exhaust gases from the combustion of the producer gas in the 10 gas engine.

11 The pelletization process required for the large-scale system is estimated to cost

$12 \$ 53.58 / \mathrm{dt}$ of residue input, and uses $15 \%$ of the biomass to supply heat for the drying of

13 the wood [26]. Residue pelletization costs are based upon KPMG's [33] estimated pellet

14 manufacturing and administration costs for a 100,000 t/yr facility in Ontario. The

15 financing cost per $t$ of pellet is calculated by estimating the fraction of the annualized 20

16 year loan payment that would be associated with the annual harvest residue inputs from

17 HFWR, and dividing the resulting cost by the annual tonnage of pellets that would be

18 produced from HFWR residue (Table 3).

\section{$20 \quad$ 2.3.4 Transportation of wood pellets to retrofitted coal-fired generating station}

The shipping costs of wood pellets to the Atikokan facility $(\$ 71.89 / \mathrm{dt}$ harvested)

23 are based on the $254 \mathrm{~km}$ trucking distance to Toronto [47], and the $1,635 \mathrm{~km}$ distance to 
1 Atikokan/Marmion Lake by rail [48]. These distances are relatively short when compared

2 with the average shipping distance to the largest markets for Canadian pellets, which are

3 in Europe [49]. As in Gan [7] and Searcy et al. [50], trucking costs are based on the

4 number of tonne-km travelled. Calculations are undertaken using the following

5 information: the operating cost per $\mathrm{km}$ for a 5 axle semi unit van in Ontario with an

6 annual utilization of $160,000 \mathrm{~km}$, assuming a $10 \%$ profit margin for the trucking

7 company ( $\$ 1.59 / \mathrm{km}$, based on [51]); the estimated round trip distance shipped; the

8 expected number of trips by truck (26.5); and a 40 tonne truck capacity. This gives a cost

9 of $\$ 735$ per truck, or 7.9 cents per tkm to transport the pellets between Haliburton and

10 Toronto.

11 Rail shipping costs for the wood pellets are based on the use of 100 tonne

12 capacity railcars [52] and a \$5,904 per railcar cost estimate from CN Rail [53]. This

13 estimate is derived from the carload price calculator on the CN Rail website, assuming an

14 origin of Toronto, a destination of Marmion Lake, Ontario, and wood pellets as the cargo

15 (commodity number 2411701). A private covered hopper car with a capacity of between

164,500 and 5,150 cubic feet would be used.

$18 \quad$ 2.3.5 Electricity and heat generation at CHP gasification facility (System 1)

The modelled CHP gasification facility, as described in Part I of the study [29],

21 includes a fixed-bed, down-draft gasifier and a cogeneration gas engine which combusts

22 the producer gas that is assumed to have an energy content of $5.2 \mathrm{MJ} / \mathrm{Nm}^{3}$ (LHV) [45].

23 Each $\mathrm{kg}$ of dry wood chips generates $2.4 \mathrm{Nm}^{3}$ of producer gas during gasification [45]. 
1 Thus, the energy conversion efficiency of the gasifier is $64.5 \%$ from dry wood chips to

2 producer gas [29], taking into account the heat inputs of the gasification reaction (0.933

3 MJ of heat per $\mathrm{Nm}^{3}$ of producer gas generated) [45]. The electrical efficiency of producer

4 gas combustion is $40 \%$, resulting in a net electrical efficiency of $25 \%$ for the entire

5 system [29]. Although a 75\% heat exchanger efficiency is assumed, the amount used is

6 considerably less: equal to the requirements for wood chip drying, the gasification

7 process, and the drying of lumber in the existing HFWR kiln. The net heat efficiency,

8 including only the heat allocated to the lumber kiln, is $3 \%$ of the energy content of the

9 biomass fuel [29].

10 For both scenarios (S1a and S1b), a $\$ 6,000 / \mathrm{kW}_{\mathrm{e}}$ estimate depicts the overall

11 capital costs for the gasifier, the producer gas cleaning and combustion infrastructure, and

12 the electricity generation and heat recovery equipment. This estimate is near the midpoint

13 of the range estimated by IRENA [54] of US $\$ 5,570 / \mathrm{kW}_{\mathrm{e}}-\$ 6,545 / \mathrm{kW}_{\mathrm{e}}$ for a CHP gasifier.

14 Although the $\$ 6,000 / \mathrm{kW}_{\mathrm{e}}$ estimate is outside of the $\$ 3,000 / \mathrm{kW}_{\mathrm{e}}-\$ 4,000 / \mathrm{kW}_{\mathrm{e}}$ cost range

15 provided in an IEA [55] report for a CHP biomass gasification and engine system, the

16 IEA [55] does not make clear if its capital cost range includes installation. We assume

17 that the small-scale system generates $1.60 * 10^{6} \mathrm{kWh}$ of electricity and displaces $6.80 * 10^{2}$

18 GJ of heat from LPG used to dry lumber at HFWR each year [29].

19 The cost of operating and maintaining a small-scale CHP gasifier is greatly

20 affected by the potential need for an operating engineer at all times while the unit is in

21 operation. With an automated system, Taljan et al. [28] based the operating cost for a 2

$22 \mathrm{MW}_{\mathrm{e}}$ wood chip combustion facility on 400 annual hours of labour at 30 Euros/hr. If a

23 similar set of assumptions is adopted for Scenario 1 (substituting a $\$ 30 / \mathrm{hr}$ wage, as in 
1 [56]), the annual operating cost estimate would be equivalent to approximately $1.0 \%$ of

2 the capital costs. For the Province of Ontario, however, there is reason to believe that the

3 annual hours of labour will be far higher due to Ontario Regulation 219/01 which states

4 that operation engineers must always be present during the operation of boilers used for

5 heat and/or electricity production [27]. It is expected that gasification-based heat and

6 electricity generation systems would be subject to the same regulation. This would

7 require approximately 6570 hours of labour per year, raising annual operating costs to

$8 \quad 16.2 \%$ of the overall capital costs. Scenario 1a uses the $1.0 \%$ estimate, reflecting the

9 absence of a requirement for the continual presence of an operating engineer, while S1b

10 uses the estimate of $16.2 \%$, based on the mandatory operating engineer regulation as it

11 currently exists in Ontario.

12 Annual maintenance and administrative costs are assumed to be $2 \%$, and $0.7 \%$ of

13 capital costs, respectively [28]. This brings the operation, maintenance, and

14 administration costs of S1a to $3.7 \%$ of capital costs, and those of S1b to $18.9 \%$. The

15 estimate for S1a is within the range suggested by Beke et al. [57], and Dornburg and

16 Faaij [6] (2001), which claim O\&M costs ranging from 3\% to 7\% of project costs for

17 wood chip cogeneration facilities. However, the estimate for S1b is far higher due to the

18 presence of the operating engineer regulation.

19 In order to estimate the net cost of electricity from both System 1 scenarios, the

20 savings from the displacement of LPG are taken into account. Approximately $680 \mathrm{GJ}$ of

21 LPG are used annually for the drying of lumber at HFWR, with the LPG cost in

22 Haliburton at 55.8 cents/litre [39]. The quantity of heat supplied by the LPG is $8.1 \%$ of

23 the net recovered heat remaining after allocating a quantity sufficient for the gasification 
1 reaction and for drying the wood chip fuel [29]. With the installation of the CHP

2 gasification facility, we assume that the current LPG gas engine associated with the kiln

3 is no longer used. Exhaust gases from the new producer gas engine are substituted as the

4 heat source for the existing lumber kiln. The sensitivity analysis (Section 6) addresses the

5 net costs if all of the unused recovered heat is used for wood drying, thus displacing

$6 \quad 3.31 * 10^{5}$ litres $\left(8.37 * 10^{3} \mathrm{GJ}\right)$ of LPG.

$8 \quad$ 2.3.6 Electricity generation at retrofitted coal-fired generating station (System 2)

10 The cost of the infrastructure modifications at Atikokan is $\$ 806 / \mathrm{KW}_{\mathrm{e}}$, based on

11 the $\$ 170$ million cost of the modifications and the $211 \mathrm{MW}_{\mathrm{e}}$ capacity of the Atikokan

12 facility [16]. The annual O\&M cost for the Atikokan facility is $\$ 21,700$ (including fixed

13 and variable costs attributed to the proposed percentage of fuel inputs from HFWR),

14 based on estimates supplied by Zhang [58] and Zhang et al. [26]. Note that the costs of

15 solid waste management are included here in the reported O\&M costs. The cost per kWh

16 of electricity generated is based on a projected capacity factor of 34\% [26] for Scenario

$172 \mathrm{a}$, and the existing capacity factor of $8 \%$ for Scenario $2 \mathrm{~b}$. The harvest residue-derived

18 wood pellets from HFWR supplied to Atikokan would comprise a very small portion of

19 the annual wood pellet supply of the facility. Using the $31.6 \%$ net electrical efficiency of

20 the Atikokan facility, approximately $1.71 * 10^{6} \mathrm{kWh}$ of electricity would be generated

21 annually from the combustion of the pellets produced from HFWR harvest residue [29].

22 As $15 \%$ of the harvest residue would be used to dry the remaining biomass to the 
1 required moisture content for the Atikokan facility [29], the net electrical efficiency

2 relative to the initial energy content of the harvest residue is $26.9 \%$.

\section{$5 \quad$ 2.3.7 Displaced coal and LPG}

In order to estimate GHG mitigation costs from replacing coal, the default cost of

8 electricity from coal is based on the assumption that the Atikokan generating station

9 would continue to burn coal indefinitely. The low $2.9 \mathrm{c} / \mathrm{kWh}$ estimate is based on the

10 default cost assumptions by Zhang et al. [26] for the Atikokan facility, and includes only

11 the O\&M and fuel costs, while assuming that the capital costs have already been paid off.

12 The prices of displaced coal-fired electricity and LPG are assumed to increase by $3 \%$

13 annually. The GHG intensities of coal $\left(1.14 \mathrm{~kg} \mathrm{CO}_{2}\right.$ eq. $\left./ \mathrm{kWh}\right)$ and $\mathrm{LPG}\left(0.0348 \mathrm{CO}_{2}\right.$ eq.

$14 \mathrm{~kg} / \mathrm{kWh}$ of electricity generated by S1) are derived from the US-EI database [59], as cited

15 in Cleary and Caspersen [29].

16

$17 \quad 3$ Results and discussion

18

$19 \quad 3.1$ Electricity generation costs

20

21 Under the favourable operational and regulatory conditions depicted in S1a and

22 S2a, the average nominal generation costs of the small-scale and large-scale systems are

2314.1 and $14.9 \mathrm{c} / \mathrm{kWh}$, respectively. When one takes into account the avoided costs of 
1 displaced LPG that would have been used for the drying of lumber in the HFWR kiln, the

2 cost per kWh for the small-scale system decreases to $13.2 \mathrm{c} / \mathrm{kWh}$ (S1a). However, under

3 existing conditions, the generation costs increase by $62 \%$ for the large-scale operation

$4 \quad(24.2 \mathrm{c} / \mathrm{kWh}-\mathrm{S} 2 \mathrm{~b})$ and $101 \%$ for the small-scale operation $(28.3 \mathrm{c} / \mathrm{kWh}-\mathrm{S} 1 \mathrm{~b})$ (Figure

5 1). The partial inflation adjustment of the FIT rates (1.5\% annually) is responsible for

$6 \quad 18 \%-20 \%$ of these cost increases. The remaining $80 \%-82 \%$ of the cost increases are

7 attributable to the more stringent regulations pertaining to the presence of a process

8 engineer on site (S1b), and to wood pellet supply limits (S2b).

9 The small-scale of the gasification system inflates the capital and operating costs

10 of the facility. Under the conditions depicted in S1a, capital and O\&M costs are

11 responsible for $72 \%$ of the cost of electricity, compared to only $20 \%$ of the costs

12 associated with the large-scale system in S2a. Under current regulatory conditions, the

13 relative share of capital and O\&M costs in total generation cost further increases to 86\%,

14 with O\&M costs contributing to $42 \%$ of the total generation cost. In both scenarios,

15 transportation and wood processing costs per kWh are much higher for the large-scale

16 wood pellet combustion system, contributing between $53 \%$ and $71 \%$ of generation costs

17 compared to the $9 \%$ to $16 \%$ range for the small-scale system. Harvest residue collection

18 is responsible for $10 \%$ or less of the generation costs. Annual corporate taxes are often

19 avoided entirely because capital depreciation tends to exceed profits throughout the 20

20 year project lives of both systems.

$22 \quad 3.2$ GHG mitigation costs 
Timing-adjusted life cycle GHG emissions of the small- and large-scale systems

2 considered here were estimated in Part I of this study [29]. Electricity generated from

3 both systems would be responsible for much lower average non-biogenic GHG emissions

4 than electricity from coal $\left(1,143 \mathrm{~g} \mathrm{CO}_{2}\right.$ eq./kWh), with the small-scale system

5 contributing $38 \mathrm{~g} / \mathrm{kWh}$ and the large-scale system contributing $134 \mathrm{~g} / \mathrm{kWh}$ (assuming a

6100 year time horizon to calculate global warming potential) [29]. The biomass

7 transportation and processing (chipping of residue and conversion to wood pellets) stages

8 of the life cycle are primarily responsible for the greater emissions from the large-scale

9 system [29]. In addition to these fossil fuel-derived emissions, harvest residue utilization

10 results in supplemental emissions because the biogenic gasification/combustion (stack)

11 emissions are greater than those which would have taken place through natural

12 decomposition under aerobic conditions [29]. However, the net annual biogenic

13 emissions from residue utilization decrease over time, until they eventually become

14 negligible [29]. When displacing coal and LPG, net GHG mitigation ensues after 4 to 7

15 years [29]. Additional detail pertaining to the calculation of net GHG emissions from the

16 two bioenergy systems is available in Cleary and Caspersen [29].

17 The GHG mitigation costs, which take into account the bioenergy costs as well as

18 the avoided costs of the displaced coal-fired electricity and LPG, are lower for the small-

19 scale facility under both scenarios. Using a 100 year time horizon for calculating global

20 warming potential, the cost of GHG mitigation under favourable conditions is $\$ 111 / \mathrm{CO}_{2}$

21 eq. for the small-scale system (S1a) and \$159/t for the large-scale system (S2a).

22 However, costs rise substantially under current conditions, reaching $\$ 265 / \mathrm{t}$ for the small-

23 scale system (S1b) and \$281/t for the large-scale system (S2b) (Figure 2). 


\section{$2 \quad 3.3$ Sensitivity analysis}

4 This sensitivity analysis addresses the effects of altering a number of the LCC

5 model parameters within plausible ranges to ascertain the extent to which variable

6 operational and regulatory conditions affect generation and mitigation costs. Two

7 parameters are varied for System 1: (1) gasification infrastructure costs; and (2) the

8 recovered heat utilized for the drying of lumber. Three parameters are altered for System

9 2: (1) wood pellet shipping distance; (2) the combustion of wood residue for pellet

10 drying; and (3) the cost of the coal-based electricity, which affects GHG mitigation costs.

11 For System 1, gasification infrastructure costs are highly uncertain, exemplified

12 by Wood and Rowley’s [32] estimate of $\$ 3000 / \mathrm{kW}_{\mathrm{e}}$ to $\$ 7000 / \mathrm{kW}_{\mathrm{e}}$. The initial cost

13 estimate of $14.1 \mathrm{c} / \mathrm{kWh}$ for $\mathrm{S} 1 \mathrm{a}$ with a capital cost of $\$ 6000 / \mathrm{kW}$ e would decrease to 9.6

$14 \mathrm{c} / \mathrm{kWh}$ with a $\$ 3000 / \mathrm{kW}_{\mathrm{e}}$ assumption, and increase to $16.8 \mathrm{c} / \mathrm{kWh}$ with a $\$ 7000 / \mathrm{kW}_{\mathrm{e}}$

15 assumption. Capital costs also rise considerably if the rated electrical capacity of the

16 bioenergy system falls below $250 \mathrm{~kW}_{\mathrm{e}}$ [60]. With regard to the sensitivity of System 1

17 costs to heat recovery, there is approximately twelve times the heat available for the

18 drying of lumber than there is kiln capacity at HFWR. If HFWR had sufficient kiln

19 capacity to use all of the recovered heat, the net cost of electricity from the small-scale

20 system would fall by $11.5 \mathrm{c} / \mathrm{kWh}$ to $2.6 \mathrm{c} / \mathrm{kWh}$ (excluding the cost of the additional kiln

21 capacity) due to the displaced LPG. This substantial reduction in costs partly reflects the

22 relatively high price of LPG, and the lack of access to lower priced natural gas (in terms

23 of MJ of energy supplied) at HFWR. 
For System 2, approximately $35 \%$ to $45 \%$ of the estimated generation cost is

2 attributable to transportation costs. Pellets for this facility could be available from sources

3 that are within closer proximity (e.g., [26], which modelled an average distance of 1,350

$4 \mathrm{~km}$, instead of $1,822 \mathrm{~km}$ ). If the wood pellet combustion facility had been located in Sault

5 Ste Marie, Ontario instead of Atikokan, the $37 \%$ reduction in pellet shipping distance by

6 rail from 1,635 km (Toronto to Marmion Lake/Atikokan) to 1,024 km (Toronto to Sault

7 Ste Marie) would decrease rail shipping costs by only $20 \%$. The overall reduction in the

8 generation cost of the large-scale system would be $0.7-0.8 \mathrm{c} / \mathrm{kWh}$. Likewise, the

9 generation cost would only decrease by $0.6-0.7 \mathrm{c} / \mathrm{kWh}$ if none of the collected residue

10 needed to be used for pellet drying at the pellet plant(s). Finally, the GHG mitigation

11 costs assessed in Section 3.2 take into account the previous cost of electricity from coal

12 combustion at Atikokan (2.9 c/kWh). However, considerable refurbishment costs might

13 have been necessary for the facility to continue generating electricity from coal

14 combustion for an additional 20 years. When using an $8 \mathrm{c} / \mathrm{kWh}$ estimate for the displaced

15 electricity from a new or refurbished coal-fired generating station (e.g., [61]), GHG

16 mitigation costs fall to $\$ 56$ and $\$ 91 / \mathrm{t} \mathrm{CO}_{2}$ eq. for $\mathrm{S} 1 \mathrm{a}$ and $\mathrm{S} 2 \mathrm{a}$, respectively. In

17 comparison, the costs of $\mathrm{S} 1 \mathrm{~b}$ are reduced to $\$ 210$, while those of $\mathrm{S} 2 \mathrm{~b}$ fall to $\$ 214 / \mathrm{t} \mathrm{CO}_{2}$

18 eq.

204 Discussion

Our results indicate that the differences in the generation costs for the two

23 systems under favourable policy conditions (S1a and S2a) are negligible, at under 1 cent. 
1 However, the current operational and regulatory constraints in Ontario increase the cost

2 of small-scale electricity generation to a much greater extent than electricity from its

3 large-scale counterpart. The co-production of electricity and heat in the small-scale CHP

4 system, and electricity generation in the retrofitted coal-fired generating station, are only

5 profitable under operational and regulatory conditions that do not currently exist in

6 Ontario. The current $15.6 \mathrm{c} / \mathrm{kWh}$ FIT for bioenergy facilities $<500 \mathrm{~kW}_{\mathrm{e}}$ in Ontario is

7 adequate compensation for undertaking the evaluated small-scale CHP project if the

8 regulation requiring the continuous presence of an operating engineer is eliminated

9 (while retaining sufficient regulation to ensure safe operation of the equipment) and

10 capital costs remain below $\sim \$ 7,000 / \mathrm{kW}_{\mathrm{e}}$. However, electricity generation costs from the

11 retrofitted coal-fired generating station are estimated at $24.2 \mathrm{c} / \mathrm{kWh}$ under current

12 operational conditions where the capacity factor of the facility is $8 \%$. This bioenergy

13 production option is unprofitable under current subsidy regimes, assuming that the

14 province allocates a subsidy amount under the new bidding/auction mechanism that is

15 similar to that allocated under the past and present FIT program (i.e., in the range of 13-

$1616 \mathrm{c} / \mathrm{kWh}$ ). If sufficient low-cost harvest residue is procured to raise the capacity factor

17 of the facility to $34 \%$, subsidy levels equal to $14.9 \mathrm{c} / \mathrm{kWh}$ or higher could provide

18 adequate compensation to support bioenergy production at the large-scale plant.

19 Our results confirmed the relatively insignificant contribution of harvest residue

20 collection to the total costs of bioenergy systems (e.g., [12]). For the small-scale system,

21 it is the capital and operating costs that predominate, whereas the capital, processing and

22 transportation costs are responsible for most of the costs of the large-scale system. O\&M

23 costs contribute to the majority of total costs under regulatory conditions mandating the 
1 presence of an engineer (S1b), which substantially increases labour costs. In contrast, for

2 the retrofitted coal-fired generating station now fueled with wood pellets, the majority of

3 total generation costs are related to the upstream activities of transportation and

4 pelletization. Given the wood pellet supply constraints that the facility is currently

5 experiencing (S2b), which has reduced the capacity factor from $34 \%$ to $8 \%$, the share of

6 capital costs in the total generation cost increases by a factor of two relative to S2a.

7 The sensitivity analysis provided additional insight into the sensitivity of the

8 generation costs of the small-scale system to capital costs and heat utilization. Generation

9 costs for S1a rise by up to $2.7 \mathrm{c} / \mathrm{kWh}$ from an increase in the assumed capital cost, and

10 fall by up to $11.5 \mathrm{c} / \mathrm{kWh}$ when assuming that all of the recovered heat from the

11 gasification reaction is used to displace LPG. The generation costs of the large-scale

12 system, on the other hand, are relatively insensitive to the varied parameters

13 (transportation distance and residue use for drying). Instead, the single most important

14 factor contributing to the generation costs of the large-scale system is not a life cycle

15 activity per se but rather related to the absolute limits of cost-effective wood pellet

16 supply.

17 An intermediate-scale CHP facility (between 2-10 $\mathrm{MW}_{\mathrm{e}}$ ) could also be a

18 promising option which would reduce the labour cost of the operating engineer relative to

19 the amount of electricity and heat generated at the bioenergy facility. As labour and

20 capital costs per $\mathrm{kWh}$ tend to decrease with scale, an intermediate-scale plant could

21 provide cost benefits relative to the small-scale CHP system addressed in our study.

22 However, biomass transportation costs would increase due to the larger biomass

23 procurement area required. The costs of biomass shipment by rail, per km, have also been 
1 shown to decrease with distance (Section 3.3). Nevertheless, the savings from lower

2 operating costs (i.e., associated with the operating engineer) would likely exceed the

3 increased transportation costs. The presence of a substantial nearby heat sink such as a

4 pellet plant would also reduce the net costs of an intermediate-scale plant. Further

5 research on the costs of bioenergy production from intermediate-scale facilities could

6 prove insightful.

7 The costs of GHG mitigation from displacing coal are higher for the large-scale

8 generating station due to the substantial quantity of GHG emissions during fuel shipping

9 and processing. The GHG balance of the small-scale CHP system is much better due to

10 the shorter total transportation distance and an improved conversion efficiency resulting

11 from heat utilization. However, there is currently insufficient justification for investing in

12 either forest bioenergy system solely on the basis of GHG emission avoidance because

13 there is no dedicated carbon tax or carbon pricing in Ontario at present. Only $12 \%$ of

14 annual global GHG emissions are subject to a carbon price, which range from under

$15 \$ 1$ (U.S.)/tonne $\mathrm{CO}_{2}$ eq. in Mexico to $\$ 168$ in Sweden [62]. Further, most of the prices in

16 existing carbon pricing systems are below $\$ 35 / t$ [62], which are insufficient for both the

17 small- and large-scale bioenergy projects.

\section{Conclusions}

21 The contrasting results for electricity generation and GHG mitigation costs

22 relative to scale have important implications for future iterations of bioenergy policies

23 that aim to encourage investment and realize attendant benefits at minimal fiscal cost. If 
1 the stated priority of Ontario's FIT program is to increase bioenergy production, the rates

2 offered should be similar for both the large- and small-scale systems under the favourable

3 operational and regulatory conditions explored here. If the primary objective of the

4 bioenergy policy is instead to reduce GHG emissions, it may be most cost-effective to

5 prioritize smaller-scale CHP systems $\left(\sim 250 \mathrm{~kW}_{\mathrm{e}}\right)$ over large-scale electricity-only

6 systems requiring long-distance fuel shipping because more GHGs are mitigated per unit

7 of government funds invested, particularly when significant local heat demand is

8 available. Results also highlight the need for broader consideration of regulatory

9 requirements and proximate fuel availability when designing supply-side policies and

10 programs focused on increasing bioenergy production from facilities of different scales.

\section{Acknowledgments}

13 This research was supported by Haliburton Forest and Wildlife Reserve, Mitacs-

14 Accelerate, the Natural Sciences and Engineering Research Council, and Ontario Power

15 Generation.

\section{References}

18 [1] Adams P, Hammond G, McManus M, Mezzullo W. 2011. Barriers to and drivers 19 for UK bioenergy development. Renewable and Sustainable Energy Reviews $20 \quad 15: 1217-1227$.

21 [2] Mayfield C, Foster C, Smith C, Gan J, Fox S. 2007. Opportunities, barriers, and 22 strategies for forest bioenergy and bio-based product development in the Southern 23 United States. Biomass and Bioenergy 31:631-637. 
1 [3] McCormick K, Kaberger T. 2007. Key barriers for bioenergy in Europe:

2 Economic conditions, know-how and institutional capacity, and supply chain co3 ordination. Biomass and Bioenergy 31:443-452.

4 [4] Moore S, Durant V, Mabee W. 2013. Determining appropriate feed-in tariff rates 5 to promote biomass-to-electricity generation in Eastern Ontario, Canada. Energy $6 \quad$ Policy 63:607-613.

7 [5] Cameron J, Kumar A, Flynn P. 2007. The impact of feedstock cost on technology $8 \quad$ selection and optimum size. Biomass and Bioenergy 31(2-3):137-144.

9 [6] Dornburg V, Faaij A. 2001. Efficiency and economy of wood-fired biomass 10 energy systems in relation to scale regarding heat and power generation using 11 combustion and gasification technologies. Biomass and Bioenergy 21:91-108.

12 [7] Gan J. 2007. Supply of biomass, bioenergy, and carbon mitigation: Method and 13 application. Energy Policy 35:6003-6009.

14 [8] Mabee W, Mannion J, Carpenter T. 2012. Comparing the feed-in tariff incentives 15 for renewable electricity in Ontario and Germany. Energy Policy 40:480-489.

16 [9] Weitzel M. 2012. Comment on "Comparing the feed-in tariff incentive for

19 [10] Ontario Power Authority (OPA). 2014. FIT/microFIT PRICE SCHEDULE

20 (January 1, 2014). Available at:

21 http://fit.powerauthority.on.ca/sites/default/files/version3/2014\%20FIT\%20Price

22 \%20Schedule_Final_20131101.pdf. Accessed on 20140620. 
1 [11] Ontario Power Authority (OPA). 2012. Bi FIT/mFIT PRICE SCHEDULE (April

2 5, 2012). Available at:

3 http://fit.powerauthority.on.ca/sites/default/files/page/FIT\%20and\%20mFIT\%20P

4 rice\%20Schedule\%20Version\%202.0.pdf. Accessed on 20141119.

5 [12] Gan J, Smith C. 2011. Optimal plant size and feedstock supply radius: A

6 modeling approach to minimize bioenergy production costs. Biomass and

7 Bioenergy 35:3350-3359.

8 [13] Jack M. 2009. Scaling laws and technology development strategies for

10 [14] Nicholls D, Monserud R, Dykstra D. 2008. Biomass utilization for bioenergy in

11 the western United States. Forest Products Journal 58(1/2):6-16.

12 [15] WIP Renewable Energies. 2009. Pellet market overview report - Europe.

13 Available at:

14 http://pelletsatlas.info/pelletsatlas_docs/showdoc.asp?id=100211172354\&type $=\mathrm{d}$

$15 \quad$ oc\&pdf=true. Accessed on 20141119.

16 [16] Ontario Power Generation (OPG). 2012. Atikokan Generating Station Biomass

17 Conversion Project Boosts Northern Economy. Available at:

18 http://www.opg.com/generating-power/thermal/stations/atikokan-

19 station/Documents/Biomass_Conversion/120719AtikokanApproved.pdf.

$20 \quad$ Accessed on 20141119.

21 [17] Ackom E, Mabee W, Saddler J. 2010. Industrial sustainability of competing wood

22 energy options in Canada. Applied Biochemistry and Biotechnology 162:2259-

232272. 
1 [18] Levin R, Krigstin S, Wetzel S. 2011. Biomass availability in eastern Ontario for

2 bioenergy and wood pellet initiatives. The Forestry Chronicle 87(1):33-41.

3 [19] Routa J, Asikainen A, Bjorheden R, Laitila J, Roser D. 2013. Forest energy

4 procurement: state of the art in Finland and Sweden. WIREs Energy and

$5 \quad$ Environment 2:602-613.

6 [20] Repo A, Kankanen R, Tuovinen J-P, Antikainen R, Tuomi M, Vanhala P, Liski J.

7 2012. Forest bioenergy climate impact can be improved by allocating forest

$8 \quad$ residue removal. GCB Bioenergy 4:201-212.

9 [21] McKechnie J, Colombo S, Chen J, Mabee W, MacLean H. 2011. Forest

10 Bioenergy or Forest Carbon? Assessing Trade-Offs in Greenhouse Gas Mitigation

11 with Wood-Based Fuels. Environmental Science and Technology 45(2):789-795.

12 [22] Marbe A, Harvey S, Berntsson T. 2004. Biofuel gasification combined heat and

13 power - new implementation opportunities resulting from combined supply of

14 process steam and district heating. Energy 29:1117-1137.

15 [23] Wei L, Filip To S, Pordesimo L, Batchelor W. 2011. Evaluation of micro-scale

16 electricity generation cost using biomass-derived synthetic gas through modeling.

17 International Journal of Energy Research 35:989-1003.

18 [24] Malkki H, Virtanen Y. 2003. Selected emissions and efficiencies of energy

19 systems based on logging and sawmill residues. Biomass and Bioenergy, 24:321-

$20 \quad 327$.

21 [25] Thornley P. 2008. Airborne emissions from biomass based power generation

22 systems. Environmental Research Letters 3:014004. 
1 [26] Zhang Y, McKechnie J, Cormier D, Lyng R, Mabee W, Ogino A, Maclean H. 2010. Life Cycle Emissions and Cost of Producing Electricity from Coal, Natural Gas, and Wood Pellets in Ontario, Canada. Environmental Science and Technology 44(1):538-544.

5 [27] Government of Ontario. 2001. Ontario regulation 219/01. Available at:

9 [28] Taljan G, Verbic G, Pantos M, Sakulin M, Fickert L. 2012. Optimal sizing of

[29] Cleary J, Caspersen J. In review. Comparing the life cycle impacts of using harvest residue as feedstock for small- and large-scale bioenergy systems (Part I). Energy.

[30] Wolf D. 2012. Adjusting Expectations of Scale Based on Limitations of Supply: A Review of the Case for a Forest Bioenergy Strategy that Prioritizes Decentralization, Efficiency, and Integration. Masters of Science in Forestry Thesis. Toronto, Ontario: University of Toronto.

[31] Danon G, Furtula M, Mandic M. 2012. Possibilities of CHP (combined heat and power) in the wood industry in Serbia. Energy 48:169-176.

[32] Wood S, Rowley P. 2011. A techno-economic analysis of small-scale, biomassfuelled combined heat and power for community housing. Biomass and Bioenergy 35:3849-3858. 
1 [33] KPMG. 2008. Wood pellet plant cost study for the Algoma and Martel Forests in

2 the western portion of the Great Lakes/St. Lawrence forest. Working Draft

3 Version 2. KPMG LLP: Sault Ste. Marie, ON, Canada. Available at:

4 http://www.canadiancleanpowercoalition.com/index.php/download_file/-

$5 \quad$ /view/94/. Accessed on 20141119.

6 [34] OPG. 2007. Rate Base and Cost of Capital. Available at:

7 http://www.opg.com/about/regulatory-affairs/Documents/stakeholder0204.pdf.

$8 \quad$ Accessed on 20140616.

9 [35] Canada Revenue Agency. 2014. Corporation tax rates. Available at:

10 http://www.cra-arc.gc.ca/tx/bsnss/tpcs/crprtns/rts-eng.html. Accessed on 201406

$11 \quad 16$.

12 [36] Ontario Ministry of Finance. 2014. Corporate Income Tax. Available at:

13 http://www.fin.gov.on.ca/en/tax/cit/. Accessed on 20140616.

14 [37] Meek P. 2012. FPInnovations. Personal communication.

15 [38] Alemdag I. 1984. Wood density variation of 28 tree species from Ontario.

16 Petawawa National Forestry Institute. Canadian Forest Service. Agriculture

17 Canada. Information report PI-X-45.

18 [39] Thompson M. 2012. Haliburton Forest and Wildlife Reserve. Personal 19 communication.

20 [40] Gmudzek P. 2012. Haliburton Forest and Wildlife Reserve. Personal 21 communication.

22 [41] Svenson G, Fjeld D. 2012. The Influence of Road Characteristics on Fuel 23 Consumption for Logging Trucks. Proceedings of HVTT 12 (12th International 
6 [42] Schleifenbaum P. 2012. Haliburton Forest and Wildlife Reserve. Personal

8 [43] FPInnovations. 2013. FPInterface ${ }^{\mathrm{TM}}$. Pointe-Claire (QC, Canada): FPInnovations.

9 [44] Cecil-Cockwell M. 2012. University of Toronto. Personal communication.

10 [45] Jungbluth N, Chudacoff M, Dauriat A, Dinkel F, Doka G, Faist Emmenegger M,

11 Gnansounou E, Kljun N, Schleiss K, Spielmann M, Stettler C, Sutter J. 2007. Life

18 [48] Szyk U. 2012. Canadian National Railway. Personal communication.

19 [49] Statistics Canada. 2012. Canadian International Merchandise Trade Database. cycle inventories of bioenergy. Ecoinvent report No. 17. Dübendorf, CH: Swiss Centre for Life Cycle Inventories.

[46] Mani S, Sokhansanj S, Bi X, Turhollow A. 2006. Economics of producing fuel pellets from biomass. Applied Engineering in Agriculture 22(3):421-426.

[47] Google. 2012. Google Maps. Available at: http://maps.google.ca/maps. Accessed on 20120515.

Table 980-0044. Domestic exports - Wood and articles of wood; wood charcoal. Top 10 countries for 2012 to which we exported trade commodity "440131 Wood pellets" from "Canada," custom basis, 6 digit commodity level. Ottawa, Ontario: Statistics Canada. 
1 [50] Searcy E, Flynn P, Ghafoori E, Kumar A. 2007. The relative cost of biomass

2 energy transport. Applied Biochemistry and Biotechnology 136-140:639-652.

3 [51] Ray Barton and Associates. 2011. Final report. Operating costs of trucking and

4 surface intermodal transportation in Canada. Transport Canada RFP File \#T8080-

$5 \quad 100234$.

6 [52] Pinnacle Renewable Energy Group. n.d. Industrial fuel pellets. Available at:

7 http://www.pinnaclepellet.com/bulk-pellets.php. Accessed on 20141118.

8 [53] Canadian National (CN) Railway. 2014. Get a carload price. Available at: http://www.cn.ca/en/shipping-prices-tariffs-get-price-freight.htm. Accessed on

11 [54] IRENA (International Renewable Energy Agency). 2012. Biomass for Power

[56] BERC (Biomass Energy Resource Center). 2009. Biomass District Energy Options for the Town of Randolph (Vermont). Pre-Feasibility Report. Available

Generation. Renewable Energy Technologies Cost Analysis Series. Vol. 1:

Power Sector. Issue 1/5. Available at: http://www.irena.org/DocumentDownloads/Publications/RE_Technologies_Cost_ Analysis-BIOMASS.pdf. Accessed on 20140624.

[55] International Energy Agency (IEA). 2007. IEA Energy Technology Essentials. Biomass for Power Generation and CHP. Available at http://www.iea.org/publications/freepublications/publication/essentials3.pdf. Accessed on 20141101 . at: http://www.vtenergyatlas-info.com/wp-content/uploads/2010/02/Randolphbiomass-CHP-I-final-study.pdf. Accessed on 20140624. 
1 [57] Beke N, Fox G, McKenney D. 1996. A financial analysis of using sawmill

2 residues for cogeneration in Northern Ontario. Energy Studies Review 8(1):16-26.

3 [58] Zhang Y. 2010. Life Cycle Environmental and Cost Evaluation of Bioenergy

4 Systems. Ph.D. dissertation. Toronto, Ontario: University of Toronto.

5 [59] Earthshift. 2013. US-EI database. Description available at:

6 http://www.earthshift.com/software/simapro/USEI-database. Accessed 201407

$7 \quad 30$.

8 [60] Buijk J. 2012. European Power Systems (EPS). Personal communication.

9 [61] IEA. 2010. Projected costs of generating electricity: 2010 edition. Available at:

10 http://www.iea.org/publications/freepublications/publication/projected_costs.pdf.

$11 \quad$ Accessed on 20141121.

12 [62] World Bank. 2014. State and trends of carbon pricing 2014. Washington, D.D.:

13 World Bank. Doi: 10.1596/978-1-4648-0268-3. 